\title{
International Society for the Study of Fatty Acids and Lipids 2018 Symposium: Arachidonic and Docosahexaenoic Acids in Infant Development
}

\author{
Joyce A. Nettleton ${ }^{\mathrm{a}} \quad$ Norman Salem Jr. ${ }^{\mathrm{b}}$

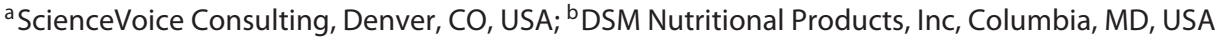

At the 13th Congress of the International Society for the Study of Fatty Acids and Lipids, Las Vegas, NV, USA, May 27-31, 2018, a satellite symposium addressed the topic, "Arachidonic and Docosahexaenoic Acids in Infant Development.” Drs. Norman Salem, Jr. and Susan Carlson co-chaired the sessions featuring 5 international leaders in this research area. The following report summarizes the presentations.

\section{Newly Discovered Elovanoids in Vision and Cognition}

Elovanoids are novel lipid mediators synthesized from very long-chain (VLC) omega-3 (n-3) polyunsaturated fatty acids (PUFA), particularly docosahexaenoic acid (DHA) or eicosapentaenoic acid (EPA), by the elongase enzyme ELOVL4. This enzyme is expressed in photoreceptor cells, neurons in several brain regions, and other tissues [1-3]. ELOVL4 generates 32- and 34-carbon n-3 VLC-PUFA from which 2 elovanoids were synthesized and characterized in the laboratory of Nicolas Bazan, Louisiana State University Neuroscience Center of Excellence, USA [2]. Unlike neuroprotectins derived from DHA, elovanoids are synthesized from n-3 VLC-PUFA

\begin{tabular}{ll}
\hline KARGER & $\begin{array}{l}\text { (c) } 2019 \text { The Author(s) } \\
\text { Published by S. Karger AG, Basel }\end{array}$ \\
E-Mail karger@karger.com & $\begin{array}{l}\text { This article is licensed under the Creative Commons Attribution- } \\
\text { NonCommercial-NoDerivatives 4.0 International License (CC BY- } \\
\text { NC-ND) (http://www.karger.com/Services/OpenAccessLicense). } \\
\text { Usage and distribution for commercial purposes as well as any dis- } \\
\text { tribution of modified material requires written permission. }\end{array}$
\end{tabular}

that are derived from chains of phospholipids and sphingolipids.

Mutations in the ELOVL4 gene result in juvenile macular degeneration, impaired neural development, neuronal dysfunction, hyper-excitability, and seizures $[4,5]$. The enzyme is also necessary for neonatal survival [6].

At a symposium held in conjunction with the 13th Congress of the International Society for the Study of Fatty Acids and Lipids, Las Vegas, NV, USA, May 27-31, 2018, Bazan presented recent data from his laboratory on the discovery of elovanoids. Mixed cultures of cerebral cortex or hippocampal neuronal cells that were deprived of oxygen and glucose for $90 \mathrm{~min}$ and then treated with N32 or N34 elovanoids showed increased cell survival after $12 \mathrm{~h}$. Similarly, these cells exhibited neuroprotection when stressed by exposure to N-methyl-D-aspartate, which exerts excitotoxicity [2]. Elovanoids clearly protected against neuronal cell death by decreasing apoptotic nuclei induced by N-methyl-D-aspartate or oxygen/ glucose deprivation.

In an animal model of ischemic stroke, elovanoid treatment reduced the volumes of the ischemic core (area of severe ischemia), penumbra (ischemic but viable tissue), and total lesion volume [2]. In related stroke experiments, elovanoid-treated animals exhibited less infarc- 
tion, improved blood vessel integrity and reduced disruption of the neurovascular unit, a mixed group of cells whose coordinated activity regulates central nervous system homeostasis [7].

Retinal pigment epithelial cells also produce elovanoids, which are active during retinal development and also have pro-survival and pro-homeostatic activities under oxidative stress [1]. Jun et al. [1] showed that they upregulate the production of several protective proteins during oxidative stress, such as sirtuin, prohibitin, and the anti-apoptotic proteins BcL2 and Bcl-xL. These and other protective activities uncovered by the Bazan's group have direct implications for juvenile macular degeneration and other neurological conditions associated with mutations in ELOVL4.

In an unpublished work, Bazan described data showing that elovanoids counteract the cell damage inflicted by the abnormal protein amyloid-beta in retinal pigment epithelial cells, photoreceptor outer segments, and extracellular deposits known as Drusen [8-10]. Other studies demonstrated the rescue of mouse retinal pigment epithelial cells damaged by amyloid-beta, protected as a result of the elovanoid-induced downregulation of senescence genes or age-related macular degeneration genes.

In summary, Bazan's laboratory discovered that elovanoids: (1) induce neuronal and retinal cell survival under oxidative stress in cultured cells; (2) have neuroprotective effects in experimental models of disease, such as ischemic stroke and traumatic brain injury; (3) counteract amyloid-beta peptide-induced cell damage that occurs in age-related macular degeneration and Alzheimer's disease; (4) enhance the abundance of pro-homeostatic proteins and decrease the abundance of proteins engaged in cell damage; (5) are active during retina and brain development; (6) may modulate transcriptome architecture to induce neuronal cell survival and regulate developmental neurogenesis.

\section{Arachidonic and DHA in Infant Development}

Many studies have documented the importance of the n-6 and n-3 long chain polyunsaturated fatty acid (LCPUFA), specifically arachidonic acid (ARA) and DHA, in the structure and function of the brain and retina $[11,12]$. These LCPUFA are actively and selectively transported across the placenta to the developing fetus $[13,14]$ and are incorporated much more effectively than for their 18-carbon precursors $[15,16]$. Physical, bio- chemical, and functional effects of n-3 LCPUFA-deficient diets have been amply described $[17,18]$.

Changes in brain function are also related to maternal and infant diets $[19,20]$, but the activities of individual n-3 PUFA remain poorly defined. It has been demonstrated, however, that provision of alpha-linolenic acid (ALA) as the main source of $\mathrm{n}-3$ PUFA during pregnancy does not promote neonatal DHA status $[15,21]$. The function and interactions of n- 6 fatty acids have not been fully described although linoleic acid (LA) is considered a negligible source of brain ARA in the rat when preformed ARA is available [22].

To investigate the interaction between ARA and EPA or DHA during growth and development Toru Moriguchi et al. [23], Azabu University, Japan, studied handreared, delta- 6 desaturase (FADS2 gene) knockout mice fed artificial formula containing different levels of ARA and DHA. This mutation eliminates the conversion of LA and ALA to their LCPUFA products, thereby preventing the in vivo production of ARA, EPA, and DHA [24]. Studies entailed 5 groups of knockout mice and 2 control groups fed artificial milk as previously described [12] containing $27 \%$ mixed fats with or without $1.2 \%$ ARA, $\mathrm{EPA}$, or DHA, or $1.2 \%$ ARA + $1.2 \%$ DHA or $1.2 \%$ ARA $+1.2 \%$ EPA with a wild-type control and a knockout control receiving $17.4 \% \mathrm{LA}$ and $4.1 \%$ ALA as the sole PUFAs. Animals were reared for 3 weeks and then weaned. At that time mice consumed a solid diet with each additional LCPUFA increased from 1.2 to $2.0 \%$ of total fatty acids for 6 more weeks. At 9 weeks of age, mice were evaluated for motor activity and coordination using the Morris water maze and the Rota-rod test. The investigators determined brain fatty acid composition at 11 weeks.

Presenting the findings from this study, Moriguchi reported that the knockout control animals weighed 30\% less than the wild-type controls [12]. Those fed ARA or ARA in combination with EPA or DHA had body weights that did not differ from the wild-type controls. Water maze results also demonstrated the longest latency, that is, poorest results in the knockout controls without LCPUFA compared with all other groups. In contrast, all groups consuming DHA with or without ARA were not different from the wild-type controls, while those consuming ARA had latencies longer than those of the wildtype controls, but not as long as the latencies of knockout controls without LCPUFA.

In the motor coordination study examining the time until the animal falls off an accelerating rotating rod, the researchers compared the duration to the wild-type control, which had the longest duration [12]. The shortest 
time was seen in the knockout controls and animals consuming only ARA. The longest duration occurred in the animals fed ARA and DHA, which was not different from the wild-type controls. The duration of the ARA and EPA group was less than the ARA and DHA group, although the difference did not reach statistical significance.

Moriguchi presented images of the small intestine that revealed hemorrhagic lesions and dark stools in 6 of the 7 mice fed DHA-only diets at 6 weeks of age. Forty percent of the knockout control mice did not survive until 11 weeks. Intestines appeared normal in all the knockout mice consuming ARA plus DHA or EPA and in those fed only EPA. Moriguchi speculated that very low levels of ARA contributed to the impaired mucosal development they observed.

When the team examined total brain weights, knockout controls exhibited significantly lower weight than the wild-type controls. Brain weights did not differ from the wild-type controls in animals consuming all ARA diets and those with only EPA. But the DHA-only mice had the lowest brain weight, even though the difference from the control did not reach statistical significance. The researchers concluded that ARA alone was sufficient to restore brain weight to control levels. In terms of PUFA composition of the hippocampus, provision of ARA and $\mathrm{ARA}+\mathrm{DHA}$ restored hippocampus LCPUFA levels to those of the wild-type controls. The addition of EPA with or without ARA did not affect DHA levels, but addition of ARA lowered levels of brain DHA relative to the wild-type controls or groups with ARA+DHA. Only the diet with both DHA and ARA restored hippocampus LCPUFA levels to that of the wild-type controls.

In order to study the interaction between ARA and DHA further, Moriguchi's team carried out a 5-week pilot study using knockout mice reared artificially as described above using the same control diet and 3 treatment diets containing $0.3 \% \mathrm{DHA}, 0.3 \% \mathrm{DHA}+0.3 \% \mathrm{ARA}$, and $0.7 \% \mathrm{ARA}+0.3 \% \mathrm{DHA}$ as a percent of total fatty acids. The investigators assessed whole brain fatty acid composition at 5 weeks of age. As expected, the total PUFA, ARA, and DHA content of the knockout control animals was markedly decreased. All groups consuming DHA showed increased levels of whole brain DHA compared with the knockout controls, while the 2 groups consuming ARA and DHA also had levels of these fatty acids comparable to the wild-type control mice. In animals fed twice as much ARA as DHA, these LCPUFA levels were indistinguishable from the wild-type control mice.

Moriguchi concluded from these studies that (1) ARA was essential for normal growth during lactation and ear- ly development; supplementation of delta- 6 desaturase knockout mice with only ARA or only DHA was insufficient for normal development; (2) only the combination of ARA + DHA was able to improve the motor and coordination dysfunction observed in animals unable to synthesize these LCPUFA; (3) preliminary data suggest that the optimum ratio of ARA:DHA to restore brain PUFA distribution in these knockout animals was $2: 1$; (4) addition of DHA only can lead to antagonism of brain ARA levels and very low peripheral levels of ARA, which were associated with hemorrhagic stools. These observations question the safety for human infants of such formulas.

\section{Early Life Exposure to DHA and ARA Results in Long-Term Differences in Brain Function}

Clinical trials of the supplementation of mothers during pregnancy or lactation with DHA with or without ARA on neurodevelopmental outcomes in the offspring have yielded mixed results [25-28]. Differences in study design, age at assessment and the use of global measurements of neurocognitive function have contributed to discrepancies among the data [29]. Studies of infants consuming diets differing in LCPUFAs have also reported inconsistent outcomes on various neurodevelopmental assessments at different ages [30-32]. Discussing some of these studies, Kathleen Gustafson, University of Kansas Medical Center, Kansas City, MO, USA, presented some of the key findings from the DIAMOND study on neurodevelopmental outcomes in infants who consumed 3 different levels of DHA in the presence of a constant amount of ARA [33].

In this randomized, double-blind, clinical trial, 122 healthy term infants (37-42 weeks gestation) consumed from birth 1 of 4 cow's milk infant formulas containing $0.32,0.64$ or $0.96 \%$ total fatty acids from DHA plus $0.64 \%$ ARA for 12 months [30]. The control group consumed unsupplemented formula. At the ages of 4, 6, and 9 months the investigators measured the sustained attention of infants defined as the time spent actually looking at a stimulus, in this case, a static color image of an adult face. Sustained attention has been strongly linked to active information processing in human infants [34]. Across all ages, infants consuming either 0.32 or $0.64 \%$ DHA had significantly greater sustained attention than the control group. Attention in the $0.94 \%$ DHA group did not differ from that in the control or the other 2 groups.

The investigators conducted another series of age-appropriate cognitive assessments when the children were 
18-72 months of age [31]. Statistically significant positive outcomes were associated with 0.32 and $0.64 \%$ DHA intakes on the Dimensional Change Card Sort task [35] and with 0.64 and $0.96 \%$ DHA levels for the Stroop task [31], although several assessments were unaffected by LCPUFA intake.

After 4 months of age, children are better able to sustain attention, filter information, implement rules and suppress or delay an anticipated response. In cognitive tests where the correct response is no response, as in the no-go phase of a go/no-go test, brain electrical activity provides a way to assess inhibitory control [36]. One such measure is the event-related potential (ERP) [37]. Although few studies have examined the effects of LCPUFA supplementation on neurodevelopmental outcomes, Gustafson's group used ERP measures to assess inhibitory control in the same LCPUFA-supplemented children at 5.5 years of age. ERP signals were also combined during times of temporary stability to reflect synchronized activation known as microstates [38]. Differences in microstates are believed to represent different experimental conditions or time sequences [39], with successive microstates representing certain information processing steps. The researchers expected to see differences in ERP and microstate measures between the LCPUFA-supplemented and control groups. Data from the various treatment groups were combined because differences among treatments were not significant.

LCPUFA-supplemented children scored higher on executive function tasks compared with unsupplemented control children, as reflected in their brain electrophysiology. Supplemented children had a faster reaction time compared with controls, with boys faster than girls. There were no group differences in the accuracy of the responses. The most striking differences occurred in contrasting conditions, especially when children had to suppress a response in the no-go part of the go/no-go test.

Three ERP measurements taken at different brain areas were assessed by amplitude and latency of response, both of which were larger for the no-go portion of the go/ no-go test than the go portion. These differences were greater for the LCPUFA-supplemented children, particularly in measurements reflecting visual processing and attention, possibly suggesting enhanced cognitive processing [40]. Similarly, the greater amplitude observed in response to the no-go part of the test could be construed as reflecting more mature forms of inhibition control. These responses are consistent with those reported by others $[41,42]$. The authors suggest that their results from the ERP analyses are consistent with previous data from the same cohort in which LCPUFA-supplemented children outperformed controls in executive function tasks involving learning rules and inhibition tasks [31]. They are also consistent with results from functional brain imaging studies in 8-10-year-old boys with low DHA status [43] and non-human primates consuming a life-long n-3 LCPUFA diet [44].

The investigators observed activation of a larger synchronized neuronal network in the LCPUFA children compared with controls using microstate analysis. The microstate reflecting the no-go condition was significantly longer in the supplemented children than in the controls, perhaps suggesting inequality between the 2 groups under conditions requiring inhibition.

Gustafson concluded that (1) LCPUFA-supplemented children have better inhibition control of learned actions compared with unsupplemented children; (2) ERP findings support previous observations suggesting that LCPUFA supplementation has a programming effect during a critical period of human development; (3) multimodal brain imaging results suggest a long-term benefit of early life DHA and ARA supplementation for attention and inhibition systems 8 years after supplementation ends.

\section{LCPUFA in Infant Formula: Clinical Results and Future Directions}

The ideal source of nutrition for infants is human milk from a well-nourished mother, but an appropriate substitute must be available if necessary. Thus, the challenge for infant formula is to provide the nutrient composition that most closely resembles the growth and developmental results achieved with human milk. In his examination of this challenge, Eric Lien, University of Illinois, Urbana, IL, USA, focused on the addition of DHA and ARA to infant formula for term infants. Breast milk contains on average approximately 1.5 times as much ARA as DHA [45]. DHA concentration is dependent on dietary intake, while ARA concentration is less so. During the first 6 months of life a breast-fed infant accrues twice as much DHA in brain as a formula-fed infant not consuming DHA [46]. Central nervous system DHA levels are sensitive to dietary DHA intake, but ARA levels are less so, suggesting tighter regulation of ARA [47]. Synthesis of DHA and ARA from their 18-carbon precursors is limited, so that preformed DHA and ARA are needed to meet the developing infant's needs $[48,49]$.

DHA concentrates in the brain and nervous system, particularly in photoreceptor outer rod segments where
Ann Nutr Metab 2019;74:83-91 DOI: $10.1159 / 000495906$
Nettleton/Salem Jr. 
it is tightly conserved. In the first 6 months of life, DHA accumulates mostly in the brain and lean tissue, but accretion is significantly reduced in infants not receiving dietary DHA [46]. The fact that DHA is important for brain and visual acuity development in infancy was demonstrated clearly in rhesus monkeys more than 30 years ago [17] and in human infants consuming DHAsupplemented infant formula [33]. Recent studies have focused on visual and nervous system development [50], fundamental neuroprotective mechanisms at the cellular and molecular level [1], and various retinal disorders [51].

A review of the early RCTs conducted in term infants consuming formula with various levels of DHA and ARA suggested that formula with DHA levels close to $0.32 \%$ total fatty acids found in breast milk [45] resulted in improved visual development compared with lower levels of DHA [52]. A more recent review recommended that infant formula provide $100 \mathrm{mg}$ DHA/day and $140 \mathrm{mg}$ ARA/ day for the first months of life, with $100 \mathrm{mg}$ DHA/day continuing for the second 6 months of life [53].

Results of DHA- and ARA-supplemented infant formula on cognitive outcomes have been mixed, but several methodological issues precluded firm conclusions [54]. In particular, assessments of global development, such as the Bayley Scales of Infant Development [55] appear insufficiently sensitive to different types of cognitive function and are of limited use, especially after 18 months of age [56]. Evaluation tools designed for more specific aspects of cognition, for example, memory and attention, provide more detailed insights into childhood cognitive development over several years.

A US cohort enrolled 122 term infants who consumed cow's milk formula containing $0.0,0.32,0.64$ or $0.96 \%$ total fatty acids as DHA for 12 months after birth. All DHA-supplemented infants also consumed $0.64 \%$ ARA, while control infants received no LCPUFA [30]. Infants were evaluated at 4, 6, and 9 months of age for sustained attention and peak look duration. Infants consuming 0.32 or $0.64 \%$ LCPUFA had longer sustained attention compared with control infants, and those consuming $0.96 \%$ LCPUFA did not differ from the 2 lower DHA groups. The investigators conducted a follow-up evaluation of 81 children at 18 months and 6 years of age [31]. In addition to Bayley Scales of Infant Development at 18 months, they included 1 or more of 8 other cognitive assessments at 6 -month intervals until age 4 , and annually thereafter until age 6 years.

LCPUFA supplementation affected some, but not all, measures of cognitive function in preschool children.
Measures of attention, rule learning and implementation, that is, Stroop scores and Dimensional Change Card Sort, were significantly higher in the combined supplementation groups than in the controls [30,31]. At ages 4 and 5, scores on verbal ability, for example, Peabody Picture Vocabulary and Wechsler Intelligence Scale, were higher in LCPUFA-supplemented children, but assessments of spatial memory, simple inhibition or advanced problemsolving did not differ. It is not surprising that a specific class of dietary nutrients (LCPUFAs) may influence some, but not all, aspects of cognitive development. The results were limited by the small sample sizes, but were consistent with other studies of maternal LCPUFA supplementation $[26,57]$.

Infants consuming formula with DHA and ARA have more desirable immune responses as assessed by markers of immune function, for example, cytokines, T-cell types and health outcomes, compared with infants fed formula without LCPUFA. Clinical studies demonstrate that consuming formula with DHA and ARA contributes to the development of a more mature immune system $[58,59]$, improves immune responses to dietary allergens [60], may reduce the risk of allergic diseases in the first year of life [61], and may reduce the risk of upper respiratory infections and diarrhea $[33,62]$.

Lien also touched on the effect of polymorphisms in the FADS 1 and FADS 2 genes, which affect the production of enzymes that convert LA and ALA to their LCPUFA derivatives, primarily ARA, EPA, and DHA. FADS genotypes may account for up to $28 \%$ of the variability in serum fatty acid levels [63]. Polymorphisms in these genes may interact with dietary LCPUFA $[64,65]$ affecting LCPUFA concentrations in breast milk, erythrocyte membranes, liver lipids, and other tissues. They have also been linked to the development of intelligence in children, coronary artery disease, acute myocardial infarction, allergic diseases, and other conditions [66] and could have implications for child health [67]. The inclusion of FADS gene polymorphisms should be considered in the assessment of future clinical trial results.

Lien emphasized the importance of including both DHA and ARA in infant formulas. Not only is ARA found in relatively constant amounts in human breast milk worldwide [45], ARA is transferred to the fetus from the mother, accumulates in brain in the first 6 months of life, and diminishes in brain with high intakes of DHA without ARA [68-70]. Although the production of formula with added DHA but no ARA has been suggested [71], experts have raised strong objections to this possibility $[56,70,72]$. 
Eyeing the future, Lien observed that the importance of ARA and DHA in infant formula continues to evolve. In addition to their established functions in vision and cognition, LCPUFA involvement in immune function and illness warrants further investigation and the effects of various FADS gene polymorphisms need to be better understood.

\section{Interaction of Infant Diet and FADS Gene Polymorphisms on Cognition and Allergy: Policy Implications}

Dietary consumption of LCPUFAs and the endogenous conversion of their $18-\mathrm{C}$ precursors LA and ALA to LCPUFA are the main determinants of tissue LCPUFA levels. Rates of precursor conversion are very low in humans [15] and are affected by genetic polymorphisms in the genes affecting the synthesis of LCPUFA [73]. The 2 most important gene clusters affecting LCPUFA production encode enzymes for fatty acid desaturation (FADS1, FADS2, FADS3) and elongation (ELOVL2). Several single nucleotide polymorphisms (SNPs) in these genes, especially the FADS gene cluster, have been identified and studied in the context of LCPUFA $[74,75]$. The effects of these polymorphisms may be associated with several health risks, including cognition and allergies in infants and children, adult obesity [76], cardiovascular disease risk [77], and low-density lipoprotein levels [78].

Dietary intake and tissue PUFA concentrations have been linked to many health outcomes, but results have often been inconsistent, especially in the areas of child cognition and allergies [67]. A relevant question is whether and to what extent genetic background and gene polymorphisms modulate responses to diet [66]. An early study in 700 adults showed that certain SNPs associated with FADS1 and FADS2 genes were strongly associated with lower levels of ARA and higher levels of LA in serum phospholipids and that carriers of these rare variants had a lower prevalence of allergic rhinitis and atopic eczema [75]. FADS1 and FADS2 SNPs are often associated with higher levels of $n-6$ precursors but have weaker effects on n-3 PUFAs $[79,80]$. These studies have been replicated in plasma and adipose tissue [81], erythrocyte membranes [82], breast milk [80], and other tissues [83], with the strongest associations reported in genome-wide association studies [84].

The effect of FADS gene polymorphisms on DHA in blood or tissues has been less well studied. Women who were homozygous ( 2 copies) for a minor FADS allele had lower proportions of DHA and ARA in plasma phospholipids and breast milk compared with carriers of the major allele $[73,85,86]$. Only women with the major allele increased breast milk DHA by consuming fish or fish oil [85]. To what extent hormones might have affected the observations is unknown, but estrogen affects LCPUFA metabolism [87, 88].

Associations between FADS gene polymorphisms and allergic diseases are inconsistent. Schaeffer reported associations of some of these variants with a lower prevalence of allergic rhinitis and atopic eczema in German adults [75]. Similarly, Rzehak et al. [74] reported a lower prevalence of eczema in a German cohort of 2-year-old children but not in Dutch children included in the same study. In neither cohort were blood PUFA levels linked to the risk of eczema. Infants exclusively breastfed for more than 5 months who carried at least 1 minor FADS gene polymorphism had a significantly reduced risk of physician-diagnosed asthma up to 10 years of age [89]. However, duration of breastfeeding had no effect on risk of asthma in those without these polymorphisms.

Barman et al. [90] examined the association between FADS gene polymorphisms and the development of allergy in a Swedish birth cohort sampled at birth and 13 years of age. They, too, observed a lower proportion of ARA in cord and adolescent serum in carriers of the gene variants. Investigators assessed allergic responses by questionnaire and genetic polymorphisms in participants who had blood samples from birth and at age 13 years. Atopic eczema or respiratory allergy were the only atopic diseases observed. Carriers of either of 2 FADS gene polymorphisms had approximately half the risk of atopic eczema at 13 years of age compared with participants having 2 major alleles, but the risk of respiratory allergy was not associated with the gene variants. Although the investigators also examined 2 variants of the ELOVL2 gene, neither was associated with allergy risk. The authors suggested that the risk of other allergic diseases might be more closely associated with n-3 LCPUFA, which are less affected by FADS polymorphisms.

Koletzko et al. concluded by noting that breastfeeding provides both ARA and DHA [91], which compensates for low LCPUFA synthesis in carriers of some FADS gene polymorphisms. Infants with gene-linked low ARA synthesis consuming formula without additional ARA might be at greater risk of asthma, eczema, or other allergic diseases and possibly suboptimal cognitive development $[67,92]$. In light of the suggestion that infant formula be supplemented only with DHA and not ARA [71], such formula would ill serve the needs of developing infants,
88

Ann Nutr Metab 2019;74:83-91 DOI: $10.1159 / 000495906$
Nettleton/Salem Jr. 
especially as FADS gene polymorphisms may affect approximately $30 \%$ of the European population [67]. He observed that formula with DHA and no ARA resulted in decreased ARA levels in erythrocytes [93] and poorer verbal IQ scores compared with infants receiving DHA and ARA [94]. ARA has different functions from DHA and is the principal unsaturated fatty acid in the inner cell membrane lipids of heart, vascular epithelium, and many other organs where it participates in diverse cellular functions [72]. He supported the conclusions of others that ARA plus DHA should be included in infant formula [68, 70].

\section{Conclusion}

Research presented at this symposium reinforced the importance of LCPUFA in infant diets and showed the continuing evolution of this field with the newly discovered elovanoids, derived from VLC n-3 PUFA. These novel lipid mediators are active during retina and brain development and have several neuronal and retinal cell survival properties. While the importance of DHA for fetal and infant brain and retinal structure and function is widely accepted, it has become clearer that ARA is also essential for normal growth and development during lactation and early childhood. More advanced measures of brain function and childhood behavior support the involvement of both DHA and ARA during critical periods of early human development that may extend into late childhood. Further, infants consuming formula with both DHA and ARA have improved immune responses and a lower risk of some allergic diseases and upper respiratory infections.

Infants carrying certain FADS gene polymorphisms affecting LCPUFA synthesis may have higher levels of LCPUFA precursors, particularly LA, and lower levels of LCPUFAs, including ARA. These alterations have been associated with a lower incidence of asthma and atopic eczema but also with possible detriments to cognitive function. Together, these diverse studies and much previous research indicate that both DHA and ARA are necessary additions to infant formula when breast milk is unavailable.

\section{Disclosure Statement and Funding Sources}

J.A.N. received funding to attend the ISSFAL 2018 symposium and prepare the manuscript from DSM Nutritional Products. All expenses for N.S. were met by his employer, DSM Nutritional Products, Inc. N.S. works for DSM Nutritional Products, which manufactures and sells products containing ARA and DHA.

\section{Authors Contribution}

The principal author was J.A.N. and N.S. reviewed and edited all drafts. Both authors approved of the final version and have agreed to be fully accountable for its contents.

\section{References}

1 Jun B, Mukherjee PK, Asatryan A, Kautzmann MA, et al: Elovanoids are novel cell-specific lipid mediators necessary for neuroprotective signaling for photoreceptor cell integrity. Sci Rep 2017;7:5279.

2 Bhattacharjee S, Jun B, Belayev L, Heap J, et al: Elovanoids are a novel class of homeostatic lipid mediators that protect neural cell integrity upon injury. Sci Adv 2017;3:e1700735.

3 Sherry DM, Hopiavuori BR, Stiles MA, Rahman NS, et al: Distribution of ELOVL4 in the developing and adult mouse brain. Front Neuroanat 2017;11:38.

4 Agbaga MP: Different mutations in ELOVL4 affect very long chain fatty acid biosynthesis to cause variable neurological disorders in humans. Adv Exp Med Biol 2016;854:129135.

5 Aldahmesh MA, Mohamed JY, Alkuraya HS, Verma IC, et al: Recessive mutations in ELOVL4 cause ichthyosis, intellectual disability, and spastic quadriplegia. Am J Hum Genet 2011;89:745-750.
6 Cameron DJ, Tong Z, Yang Z, Kaminoh J, et al: Essential role of Elovl4 in very long chain fatty acid synthesis, skin permeability barrier function, and neonatal survival. Int J Biol Sci 2007;3:111-119.

7 Muoio V, Persson PB, Sendeski MM: The neurovascular unit - concept review. Acta Physiol (Oxf) 2014;210:790-798.

8 Dong ZZ, Li J, Gan YF, Sun XR, et al: Amyloid beta deposition related retinal pigment epithelium cell impairment and subretinal microglia activation in aged APPswePS1 transgenic mice. Int J Ophthalmol 2018;11:747755.

9 Hoh Kam J, Lenassi E, Jeffery G: Viewing ageing eyes: diverse sites of amyloid beta accumulation in the ageing mouse retina and the up-regulation of macrophages. PLoS One 2010;5:pii:e13127.

10 Ratnayaka JA, Serpell LC, Lotery AJ: Dementia of the eye: the role of amyloid beta in retinal degeneration. Eye (Lond) 2015;29:10131026.
11 Innis SM: Fatty acids and early human development. Early Hum Dev 2007;83:761-766.

12 Harauma A, Yasuda H, Hatanaka E, Nakamura MT, et al: The essentiality of arachidonic acid in addition to docosahexaenoic acid for brain growth and function. Prostaglandins Leukot Essent Fatty Acids 2017;116:9-18.

13 Innis SM: Essential fatty acid transfer and fetal development. Placenta 2005;26(suppl A): S70-S75.

14 Crawford MA, Hassam AG, Williams G: Essential fatty acids and fetal brain growth. Lancet 1976;1:452-453.

15 Brenna JT, Salem N Jr, Sinclair AJ, Cunnane SC, et al: Alpha-Linolenic acid supplementation and conversion to n-3 long-chain polyunsaturated fatty acids in humans. Prostaglandins Leukot Essent Fatty Acids 2009;80:85-91.

16 Greiner RC, Winter J, Nathanielsz PW, Brenna JT: Brain docosahexaenoate accretion in fetal baboons: bioequivalence of dietary alpha-linolenic and docosahexaenoic acids. Pediatr Res 1997;42:826-834. 
17 Neuringer M, Connor WE, Lin DS, Barstad L, et al: Biochemical and functional effects of prenatal and postnatal omega 3 fatty acid deficiency on retina and brain in rhesus monkeys. Proc Natl Acad Sci U S A 1986;83:40214025.

18 Connor WE, Neuringer M: The effects of n-3 fatty acid deficiency and repletion upon the fatty acid composition and function of the brain and retina. Prog Clin Biol Res 1988;282: 275-294.

19 Auestad N, Scott DT, Janowsky JS, Jacobsen $\mathrm{C}$, et al: Visual, cognitive, and language assessments at 39 months: a follow-up study of children fed formulas containing longchain polyunsaturated fatty acids to 1 year of age. Pediatrics 2003;112(3 pt 1):e177e183.

20 Muskiet FA, van Goor SA, Kuipers RS, Velzing-Aarts FV, et al: Long-chain polyunsaturated fatty acids in maternal and infant nutrition. Prostaglandins Leukot Essent Fatty Acids 2006; 75:135-144.

21 de Groot RH, Hornstra G, van Houwelingen AC, Roumen F: Effect of alpha-linolenic acid supplementation during pregnancy on maternal and neonatal polyunsaturated fatty acid status and pregnancy outcome. Am J Clin Nutr 2004;79:251-260.

22 DeMar JC Jr, Lee HJ, Ma K, Chang L, et al: Brain elongation of linoleic acid is a negligible source of the arachidonate in brain phospholipids of adult rats. Biochim Biophys Acta 2006; 1761:1050-1059.

23 Hatanaka E, Harauma A, Yasuda H, Watanabe J, et al: Essentiality of arachidonic acid intake in murine early development. Prostaglandins Leukot Essent Fatty Acids 2016;108: 51-57.

24 Stoffel W, Holz B, Jenke B, Binczek E, et al: Delta6-desaturase (FADS2) deficiency unveils the role of omega3- and omega6-polyunsaturated fatty acids. EMBO J 2008;27:22812292.

25 Gibson RA, Neumann MA, Makrides M: Effect of increasing breast milk docosahexaenoic acid on plasma and erythrocyte phospholipid fatty acids and neural indices of exclusively breast fed infants. Eur J Clin Nutr 1997; 51:578-584.

26 Helland IB, Smith L, Saarem K, Saugstad OD, et al: Maternal supplementation with verylong-chain n-3 fatty acids during pregnancy and lactation augments children's IQ at 4 years of age. Pediatrics 2003;111:e39-e44.

27 Makrides M, Neumann MA, Simmer K, Gibson RA: A critical appraisal of the role of dietary long-chain polyunsaturated fatty acids on neural indices of term infants: a randomized, controlled trial. Pediatrics 2000;105(1 pt 1):32-38.

28 Drover JR, Hoffman DR, Castaneda YS, Morale SE, et al: Cognitive function in 18-monthold term infants of the DIAMOND study: a randomized, controlled clinical trial with multiple dietary levels of docosahexaenoic acid. Early Hum Dev 2011;87:223-230.
29 Cheatham CL, Colombo J, Carlson SE: N-3 fatty acids and cognitive and visual acuity development: methodologic and conceptual considerations. Am J Clin Nutr 2006;83(6 suppl):1458S-1466S.

30 Colombo J, Carlson SE, Cheatham CL, Fitzgerald-Gustafson KM, et al: Long-chain polyunsaturated fatty acid supplementation in infancy reduces heart rate and positively affects distribution of attention. Pediatr Res 2011;70:406-410.

31 Colombo J, Carlson SE, Cheatham CL, Shaddy DJ, et al: Long-term effects of LCPUFA supplementation on childhood cognitive outcomes. Am J Clin Nutr 2013;98:403-412.

32 Willatts P, Forsyth S, Agostoni C, Casaer P, et al: Effects of long-chain PUFA supplementation in infant formula on cognitive function in later childhood. Am J Clin Nutr 2013;98: 536S-542S.

33 Birch EE, Carlson SE, Hoffman DR, Fitzgerald-Gustafson KM, et al: The DIAMOND (DHA intake and measurement of neural development) Study: a double-masked, randomized controlled clinical trial of the maturation of infant visual acuity as a function of the dietary level of docosahexaenoic acid. Am J Clin Nutr 2010;91:848-859.

34 Colombo J, Richman WA, Shaddy DJ, Greenhoot AF, et al: Heart rate-defined phases of attention, look duration, and infant performance in the paired-comparison paradigm. Child Dev 2001;72:1605-1616.

35 Zelazo PD: The dimensional change card sort (DCCS): a method of assessing executive function in children. Nat Protoc 2006;1:297301.

36 Liao K, McCandliss BD, Carlson SE, Colombo $\mathrm{J}$, et al: Event-related potential differences in children supplemented with long-chain polyunsaturated fatty acids during infancy. Dev Sci 2017;20.

37 Bokura H, Yamaguchi S, Kobayashi S: Electrophysiological correlates for response inhibition in a Go/NoGo task. Clin Neurophysiol 2001;112:2224-2232.

38 Lehmann D, Ozaki H, Pal I: EEG alpha map series: brain micro-states by space-oriented adaptive segmentation. Electroencephalogr Clin Neurophysiol 1987;67:271-288.

39 Michel CM, Murray MM, Lantz G, Gonzalez $S$, et al: EEG source imaging. Clin Neurophysiol 2004; 115:2195-2222.

40 Freunberger R, Klimesch W, Doppelmayr M, Holler Y: Visual P2 component is related to theta phase-locking. Neurosci Lett 2007;426: 181-186.

41 Lewis MD, Lamm C, Segalowitz SJ, Stieben J, et al: Neurophysiological correlates of emotion regulation in children and adolescents. J Cogn Neurosci 2006;18:430-443.

42 Kenemans JL, Bekker EM, Lijffijt M, Overtoom CC, et al: Attention deficit and impulsivity: selecting, shifting, and stopping. Int J Psychophysiol 2005;58:59-70.

43 McNamara RK, Jandacek R, Tso P, Weber W, et al: Low docosahexaenoic acid status is as- sociated with reduced indices in cortical integrity in the anterior cingulate of healthy male children: a $1 \mathrm{H}$ MRS Study. Nutr Neurosci 2013;16:183-190.

44 Grayson DS, Kroenke CD, Neuringer M, Fair DA: Dietary omega-3 fatty acids modulate large-scale systems organization in the rhesus macaque brain. J Neurosci 2014;34:20652074.

45 Brenna JT, Varamini B, Jensen RG, DiersenSchade DA, et al: Docosahexaenoic and arachidonic acid concentrations in human breast milk worldwide. Am J Clin Nutr 2007;85: 1457-1464.

46 Cunnane SC, Francescutti V, Brenna JT, Crawford MA: Breast-fed infants achieve a higher rate of brain and whole body docosahexaenoate accumulation than formula-fed infants not consuming dietary docosahexaenoate. Lipids 2000;35:105-111.

47 Hsieh AT, Brenna JT: Dietary docosahexaenoic acid but not arachidonic acid influences central nervous system fatty acid status in baboon neonates. Prostaglandins Leukot Essent Fatty Acids 2009;81:105-110.

48 Demmelmair H, von Schenck U, Behrendt E, Sauerwald T, et al: Estimation of arachidonic acid synthesis in full term neonates using natural variation of $13 \mathrm{C}$ content. J Pediatr Gastroenterol Nutr 1995;21:31-36.

49 Salem N Jr, Wegher B, Mena P, Uauy R: Arachidonic and docosahexaenoic acids are biosynthesized from their 18-carbon precursors in human infants. Proc Natl Acad Sci U S A 1996;93:49-54

50 Rogers LK, Valentine CJ, Keim SA: DHA supplementation: current implications in pregnancy and childhood. Pharmacol Res 2013; 70:13-19.

51 SanGiovanni JP, Chew EY: The role of omega-3 long-chain polyunsaturated fatty acids in health and disease of the retina. Prog Retin Eye Res 2005;24:87-138.

52 Hoffman DR, Boettcher JA, Diersen-Schade DA: Toward optimizing vision and cognition in term infants by dietary docosahexaenoic and arachidonic acid supplementation: a review of randomized controlled trials. Prostaglandins Leukot Essent Fatty Acids 2009;81: 151-158.

53 Koletzko B, Boey CC, Campoy C, Carlson SE, et al: Current information and Asian perspectives on long-chain polyunsaturated fatty acids in pregnancy, lactation, and infancy: systematic review and practice recommendations from an early nutrition academy workshop. Ann Nutr Metab 2014;65:49-80.

54 Meldrum SJ, Smith MA, Prescott SL, Hird K, et al: Achieving definitive results in longchain polyunsaturated fatty acid supplementation trials of term infants: factors for consideration. Nutr Rev 2011;69:205-214.

55 Albers CA, Grieve AJ: Test review; in Bayley N (2006): Bayley Scales of Infant and Toddler Development-Third (ed). J Psychoeducational Assessment. San Antonio, Harcourt Assessment, 2007, vol 25, pp 180-198. 
56 Lien EL, Richard C, Hoffman DR: DHA and ARA addition to infant formula: Current status and future research directions. Prostaglandins Leukot Essent Fatty Acids 2018;128:26-40.

57 Jensen CL, Voigt RG, Llorente AM, Peters SU, et al: Effects of early maternal docosahexaenoic acid intake on neuropsychological status and visual acuity at five years of age of breastfed term infants. J Pediatr 2010;157:900-905.

58 Richard C, Lewis ED, Field CJ: Evidence for the essentiality of arachidonic and docosahexaenoic acid in the postnatal maternal and infant diet for the development of the infant's immune system early in life. Appl Physiol Nutr Metab 2016;41:461-475.

59 Field CJ, Van Aerde JE, Robinson LE, Clandinin MT: Effect of providing a formula supplemented with long-chain polyunsaturated fatty acids on immunity in full-term neonates. Br J Nutr 2008;99:91-99.

60 Field CJ, Van Aerde JE, Robinson LE, Clandinin MT: Feeding a formula supplemented with long chain polyunsaturated fatty acids modifies the "ex vivo" cytokine responses to food proteins in infants at low risk for allergy. Pediatr Res 2008;64:411-417.

61 Foiles AM, Kerling EH, Wick JA, Scalabrin $\mathrm{DM}$, et al: Formula with long-chain polyunsaturated fatty acids reduces incidence of allergy in early childhood. Pediatr Allergy Immunol 2016;27:156-161.

62 Lapillonne A, Pastor N, Zhuang W, Scalabrin DM: Infants fed formula with added long chain polyunsaturated fatty acids have reduced incidence of respiratory illnesses and diarrhea during the first year of life. BMC Pediatr 2014;14:168.

63 Gieger C, Geistlinger L, Altmaier E, Hrabé de Angelis $\mathrm{M}$, et al: Genetics meets metabolomics: a genome-wide association study of metabolite profiles in human serum. PLoS Genet 2008; 4:e1000282.

64 Chen Y, Estampador AC, Keller M, Poveda A, et al: The combined effects of FADS gene variation and dietary fats in obesity-related traits in a population from the far north of Sweden: the GLACIER Study. Int J Obes (Lond) 2018, Epub ahead of print.

65 Ding Z, Liu GL, LiX, Chen XY, et al: Association of polyunsaturated fatty acids in breast milk with fatty acid desaturase gene polymorphisms among Chinese lactating mothers. Prostaglandins Leukot Essent Fatty Acids 2016;109:66-71.

66 Lattka E, Illig T, Heinrich J, Koletzko B: Do FADS genotypes enhance our knowledge about fatty acid related phenotypes? Clin Nutr 2010;29:277-287.

67 Lattka E, Klopp N, Demmelmair H, Klingler $\mathrm{M}$, et al: Genetic variations in polyunsaturated fatty acid metabolism - implications for child health? Ann Nutr Metab 2012;60(suppl 3):8-17.

68 Brenna JT: Arachidonic acid needed in infant formula when docosahexaenoic acid is present. Nutr Rev 2016;74:329-336.

69 Kuipers RS, Luxwolda MF, Offringa PJ, Boersma ER, et al: Fetal intrauterine whole body lin- oleic, arachidonic and docosahexaenoic acid contents and accretion rates. Prostaglandins Leukot Essent Fatty Acids 2012;86:13-20.

70 Koletzko B, Carlson SE, van Goudoever JB: Should infant formula provide both omega-3 DHA and omega-6 arachidonic acid? Ann Nutr Metab 2015;66:137-138.

71 EFSA Panel on Dietetic Products NaAN: Scientific opinion on the essential composition of infant and follow-on formulae. EFSA J 2014;12:3760-3866.

72 Crawford MA, Wang Y, Forsyth S, Brenna JT: The European Food Safety Authority recommendation for polyunsaturated fatty acid composition of infant formula overrules breast milk, puts infants at risk, and should be revised. Prostaglandins Leukot Essent Fatty Acids 2015;102-103:1-3

73 Koletzko B, Lattka E, Zeilinger S, Illig T, et al Genetic variants of the fatty acid desaturase gene cluster predict amounts of red blood cell docosahexaenoic and other polyunsaturated fatty acids in pregnant women: findings from the Avon Longitudinal Study of Parents and Children. Am J Clin Nutr 2011;93:211-219.

74 Rzehak P, Heinrich J, Klopp N, Schaeffer L, et al: Evidence for an association between genetic variants of the fatty acid desaturase 1 fatty acid desaturase 2 (FADS1 FADS2) gene cluster and the fatty acid composition of erythrocyte membranes. Br J Nutr 2009;101:20-26.

75 Schaeffer L, Gohlke H, Müller M, Heid IM, et al: Common genetic variants of the FADS1 FADS2 gene cluster and their reconstructed haplotypes are associated with the fatty acid composition in phospholipids. Hum Mol Genet 2006;15:1745-1756.

76 Li K, Brennan L, Bloomfield JF, Duff DJ, et al: Adiposity associated plasma linoleic acid is related to demographic, metabolic health and haplotypes of FADS1/2 genes in Irish adults. Mol Nutr Food Res 2018;62:e1700785.

77 O'Neill CM, Minihane AM: The impact of fatty acid desaturase genotype on fatty acid status and cardiovascular health in adults. Proc Nutr Soc 2017;76:64-75.

78 Kwak JH, Paik JK, Kim OY, Jang Y, et al: FADS gene polymorphisms in Koreans: association with omega6 polyunsaturated fatty acids in serum phospholipids, lipid peroxides, and coronary artery disease. Atherosclerosis 2011;214:94-100.

79 Bokor S, Dumont J, Spinneker A, GonzalezGross M, et al: Single nucleotide polymorphisms in the FADS gene cluster are associated with delta- 5 and delta- 6 desaturase activities estimated by serum fatty acid ratios. J Lipid Res 2010;51:2325-2333.

80 Xie L, Innis SM: Genetic variants of the FADS1 FADS2 gene cluster are associated with altered $(n-6)$ and (n-3) essential fatty acids in plasma and erythrocyte phospholipids in women during pregnancy and in breast milk during lactation. J Nutr 2008;138:2222-2228.

81 Baylin A, Ruiz-Narvaez E, Kraft P, Campos H: alpha-Linolenic acid, Delta6-desaturase gene polymorphism, and the risk of nonfatal myo- cardial infarction. Am J Clin Nutr 2007;85: 554-560.

82 Malerba G, Schaeffer L, Xumerle L, Klopp N, et al: SNPs of the FADS gene cluster are associated with polyunsaturated fatty acids in a cohort of patients with cardiovascular disease. Lipids 2008;43:289-299.

83 Reynolds LM, Howard TD, Ruczinski I, Kanchan K, et al: Tissue-specific impact of FADS cluster variants on FADS1 and FADS2 gene expression. PLoS One 2018;13:e0194610.

84 Tanaka T, Shen J, Abecasis GR, Kisialiou A, et al: Genome-wide association study of plasma polyunsaturated fatty acids in the InCHIANTI Study. PLoS Genet 2009;5:e1000338.

85 Moltó-Puigmartí C, Plat J, Mensink RP, Müller A, et al: FADS1 FADS2 gene variants modify the association between fish intake and the docosahexaenoic acid proportions in human milk. Am J Clin Nutr 2010;91:1368-1376.

86 Lattka E, Rzehak P, Szabó É, Jakobik V, et al: Genetic variants in the FADS gene cluster are associated with arachidonic acid concentrations of human breast milk at 1.5 and 6 mo postpartum and influence the course of milk dodecanoic, tetracosenoic, and trans-9-octadecenoic acid concentrations over the duration of lactation. Am J Clin Nutr 2011;93:382-391.

87 Oosthuyse T, Bosch AN: Oestrogen's regulation of fat metabolism during exercise and gender specific effects. Curr Opin Pharmacol 2012;12:363-371.

88 Burdge GC, Wootton SA: Conversion of alpha-linolenic acid to eicosapentaenoic, docosapentaenoic and docosahexaenoic acids in young women. Br J Nutr 2002;88:411-420.

89 Standl M, Sausenthaler S, Lattka E, Koletzko $S$, et al: FADS gene cluster modulates the effect of breastfeeding on asthma. Results from the GINIplus and LISAplus studies. Allergy 2012;67:83-90.

90 Barman M, Nilsson S, Torinsson Naluai A, Sandin A, et al: Single nucleotide polymorphisms in the FADS gene cluster but not the ELOVL2 gene are associated with serum polyunsaturated fatty acid composition and development of allergy (in a Swedish birth cohort). Nutrients 2015;7:10100-10115.

91 Koletzko B: Human milk lipids. Ann Nutr Metab 2016;69(suppl 2):28-40.

92 Cheatham CL, Lupu DS, Niculescu MD: Genetic and epigenetic transgenerational implications related to omega- 3 fatty acids. Part II: maternal FADS2 rs174575 genotype and DNA methylation predict toddler cognitive performance. Nutr Res 2015;35:948-955.

93 Makrides M, Neumann MA, Simmer K, Gibson RA: Erythrocyte fatty acids of term infants fed either breast milk, standard formula, or formula supplemented with long-chain polyunsaturates. Lipids 1995;30:941-948.

94 Birch EE, Garfield S, Castañeda Y, Hughbanks-Wheaton D, et al: Visual acuity and cognitive outcomes at 4 years of age in a doubleblind, randomized trial of long-chain polyunsaturated fatty acid-supplemented infant formula. Early Hum Dev 2007;83:279-284. 